\title{
The Characteristics and Laterality of Explosive Force Exertion of Hand Grip and Toe Grip
}

\author{
Masakatsu Nakada', Shinichi Demura² \\ ${ }^{1}$ National Defense Academy of Japan, Yokosuka, Japan \\ ${ }^{2}$ Graduate School of Natural Science \& Technology, Kanazawa University, Kanazawa, Japan \\ Email: nakada@nda.ac.jp
}

Received 4 August 2014; revised 6 September 2014; accepted 6 October 2014

Copyright (C) 2014 by authors and Scientific Research Publishing Inc.

This work is licensed under the Creative Commons Attribution International License (CC BY). http://creativecommons.org/licenses/by/4.0/

(c) (i) Open Access

\section{Abstract}

This study examines the force exertion characteristics and laterality of maximal explosive force exertion of hand grip and toe grip. Fifteen male subjects, aged 19 to 23 years, performed maximal explosive hand grip and toe grip exertions with their dominant and non-dominant sides. Maximal force value and integral force for $\mathbf{2}$ sec in the hand grip exertions were significantly larger than those in the toe grip exertions in both the dominant and non-dominant sides. The time required to achieve $\mathbf{9 0 \%}$ maximal force value in the hand grip exertions was significantly shorter than that in the toe grip exertions in both sides. Correlations between the dominant and non-dominant sides were significant $(r=0.710-0.889)$ in maximal force value and integral force for 2 sec during the hand and toe grip exertions, but they were not significant (hand grip: $r=0.242$, toe grip: $r=0.032$ ) with respect to the time taken to achieve $\mathbf{9 0 \%}$ maximal force value. In conclusion, a force exertion value increases more quickly in an explosive hand grip than that in an explosive toe grip. The laterality may relate to time parameters in both explosive force exertions, but not to ones related to force.

\section{Keywords}

Explosive Force Exertion, Hand Grip, Toe Grip

\section{Introduction}

People prefer the dominant hand or arm for their upper limbs, but for their lower limbs they often use their legs simultaneously by walking or running. During standing, the feet are in constant contact with the soles of the 
footwear, and they exert force unintentionally; but the hands are free to be used intentionally. Hence, the characteristics of force exertion of the arms and legs differ.

Until now, studies on handgrip have been mainly performed by using the dominant hand (Demura et al., 1999; Nakada \& Demura, 2013; Nakada et al., 2005; Yamaji et al., 2002; Yamaji et al., 2000). Meanwhile, a previous study examined the toes during bipedal walking (Hughes et al., 1990). The frequency of use of the right and left sides in daily life differs considerably for the arms and legs. A strength decrease of the right and left arms or legs may also differ, such as when a dominant arm or leg cannot be used due to injury. Hence, in evaluating muscle function it is important to clarify the characteristics of the hand and toe grips, in addition to the arms and legs and their laterality.

Demura et al. (2010a) examined the exertion characteristics of isometric, isotonic, and isokinetic muscle powers of elbow flexion in the dominant and non-dominant arms and reported that the dominant arm was superior to the non-dominant hand in isometric and isotonic muscle power, but not in isokinetic muscle power. In addition, Miyaguchi \& Demura (2008) reported that the stretch-shortening cycle (SSC) index of the non-dominant arm using SSC movement by elbow flexion was larger than that of the dominant arm. However, it has been found that the isokinetic strength of lower limbs showed no significant differences between dominant and non-dominant legs (Holmes \& Alderink, 1984). As described above, the laterality of force exertion characteristics may be different by force exertion style and exertion regions. It has been reported that the controlled force exertion using handgrip has laterality (Kubota \& Demura, 2011; Noguchi et al., 2009). In addition, Aoki \& Demura (2008) examined the laterality of handgrip power and elbow flexion power. However, the laterality of explosive force exertion in the hand and toe grips has not been studied thoroughly.

Demura et al. (1999) examined the force exertion characteristics of the development phase during explosive force exertion using a handgrip device. A similar study using both hand and toe grip devices may facilitate a comparison of both force exertion characteristics.

The purpose of this study was to clarify the explosive force exertion characteristics of the dominant and nondominant sides in the hand and toe grips and their laterality.

\section{Methods}

\subsection{Subjects}

The subjects were 15 males (height: $172.5 \pm 3.1 \mathrm{~cm}$, weight: $73.1 \pm 10.0 \mathrm{~kg}$ ) aged 19 - 23 years, all of whom were regularly involved in sports. Informed consent was obtained from all subjects after explaining the experimental purpose, procedure, and methods in detail. This study protocol was approved by the Ethics Committee on Human Experimentation of Faculty of Human Science, Kanazawa University (No. 2012-02).

\subsection{Experiment Devices}

A $20 \mathrm{~Hz}$ sampling rate handgrip sensor (EG-210, Sakai Medical. Co., Ltd., Tokyo, Japan) using appropriate software EG-290, Sakai Medical. Co., Ltd., Tokyo, Japan) on a personal computer and an indicator (EG-220, Sakai Medical. Co., Ltd., Tokyo, Japan) were used to measure the hand grip. A toe finger dynamometer (T.K.K. 3361, Takei Scientific Instruments Co., Ltd., Niigata, Japan) was used to measure the toe grip. Data were sampled at $20 \mathrm{~Hz}$ on a computer by an A/D converter (Power Lab/16sp, AD Instruments).

\subsection{Measurement}

\subsubsection{Decision of the Dominant Hand and Dominant Foot}

The dominant hand and foot were determined by a survey based on the reports of Demura et al. (2009) and Demura et al. (2010b). Fourteen males were right-handed, while one was left-handed. Fourteen males were rightfooted, while one was left-footed.

\subsubsection{Measurement of the Hand and Toe Grip Exertions}

Each subject performed maximal hand grip exertion with the right hand while seated in a chair. The measurement was performed twice at a 90-degree angle between the trunk and the arm, which rested on a desk. The larger grip strength was selected as a representative value. The measurement of the explosive hand grip exertion was performed using methods based on the report of Demura et al. (1999). After a signal, the subjects exerted 
explosive hand grip in the same posture as when measuring maximal strength, and after 5 seconds the signal to cease was sounded. They performed two trials, and the maximal and explosive grips with the left hand were measured twice in the same method.

For each subject, maximal toe grip strength with the right foot was measured before explosive toe grip. These measurements were performed twice seated in a chair with the knee joints kept at a 90-degree angle (Figure 1). The larger grip value was selected as the representative value. Explosive toe grip exertion was measured by methods based on the report of Demura et al. (1999). After a signal, the subjects performed explosive toe gripping on the bar of a dynamometer in the same posture as the second measurement of maximal toe strength. After five seconds, the end signal was given. Then, the measurement of maximal toe grip and explosive toe grip with the left foot was performed twice.

\subsection{Parameters and Analysis}

From the study of Demura et al. (1999) were selected the parameters regarding maximum strength during explosive force exertion (maximal force value), the time until maximal force value (time to maximal force value), the time until $90 \%$ value of maximal force value (time to $90 \%$ maximal force value), and integrated force value until 2 seconds $(20 \mathrm{~Hz})$ after the beginning of the force exertion (integral force for $2 \mathrm{~s}$ ).

The paired t-test was used to examine the mean difference between maximal hand grip strength and maximal toe grip strength. Two-way (hand/toe grip $\times$ dominant/non-dominant) ANOVA were used to examine the mean differences among force exertion regions (hand, toe) and laterality (dominant, non-dominant) for each parameter. Post hoc-test by Bonferroni method was used for multiple comparisons, if interactions or main effects showed any significance. In addition, the relationship between the dominant and non-dominant sides for each parameter was examined using Pearson's correlation coefficient. The significant level of this study was set at 5\%.

\section{Results}

Maximal hand grip strength (dominant hand: mean $=48.3 \mathrm{~kg}$, non-dominant hand: mean $=44.6 \mathrm{~kg}$ ) showed a significant difference between the dominant and non-dominant hands $(t=3.884, p=0.002)$. Maximal toe grip strength (dominant toe: mean $=17.8 \mathrm{~kg}$, non-dominant toe: mean $=16.1 \mathrm{~kg}$ ) showed no significant differences between the dominant and the non-dominant toes $(\mathrm{t}=1.960, p=0.07)$.

Figure 2 shows the changes of the force values during explosive hand and toe grip exertion with the dominant and non-dominant sides. The force curve in the former was similar between the dominant and non-dominant hands, and the force value tended to reach maximal force value rapidly after exertion started, as compared with explosive toe grip exertion.

Table 1 shows the results of two-way (hand/toe grip $\times$ dominant/non-dominant) ANOVA for parameters during explosive force exertion. Maximal force value, time to achieve $90 \%$ maximal force value, and integral force for 2 sec showed a significant main effect in hand/toe grips. Multiple comparisons showed that maximal force value and integral force for 2 sec were larger in the hand grip than in the toe grip in both dominant and non-dominant sides. Time to $90 \%$ maximal force value was shorter in the hand grip than in the toe grip on both sides. Time to maximal force value showed no significant main effects.

Table 2 shows Pearson's correlations between the dominant and non-dominant sides for parameters during explosive force exertion. Maximal force value and integral force for 2 sec showed significant values in both grips, but time to maximal force was needed only in hand grip. In addition, time to $90 \%$ maximal force value

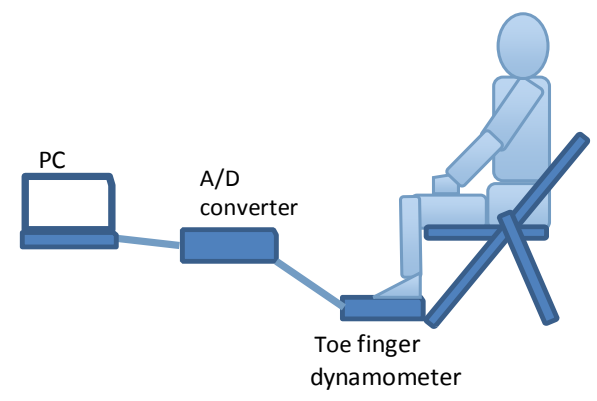

Figure 1. Measurement of the toe grip exertion. 


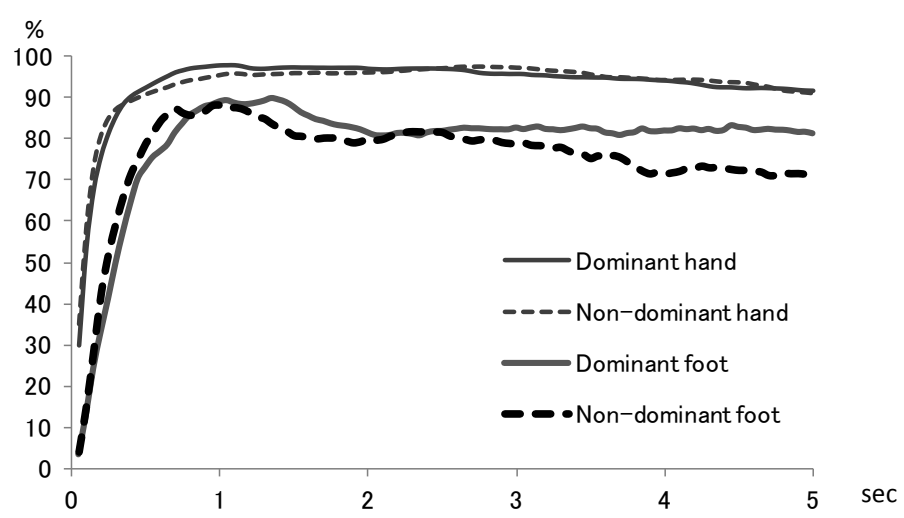

Figure 2. Changes of force values during explosive hand and toe grip exertion using dominant and non-dominant sides.

Table 1. Results of two-way (hand/toe grip $\times$ dominant/non-dominant) ANOVA for parameters.

\begin{tabular}{|c|c|c|c|c|c|c|c|c|c|c|c|c|c|c|}
\hline & & \multicolumn{4}{|c|}{ Hand grip } & \multicolumn{4}{|c|}{ Toe grip } & & \multirow{3}{*}{ F-value } & \multirow{3}{*}{$p$} & \multirow{3}{*}{ Partial $\eta^{2}$} & \multirow{3}{*}{$\begin{array}{l}\text { Multiple } \\
\text { comparison }\end{array}$} \\
\hline & & \multicolumn{2}{|c|}{ Dominant } & \multicolumn{2}{|c|}{ Non-dominant } & \multicolumn{2}{|c|}{ Dominant } & \multicolumn{2}{|c|}{ Non-dominant } & & & & & \\
\hline & & Mean & SD & Mean & SD & Mean & SD & Mean & SD & & & & & \\
\hline \multirow{3}{*}{$\begin{array}{l}\text { Maximal } \\
\text { force value }\end{array}$} & \multirow{3}{*}{$\mathrm{kg}$} & \multirow{3}{*}{45.7} & \multirow{3}{*}{8.7} & \multirow{3}{*}{44.5} & \multirow{3}{*}{6.3} & \multirow{3}{*}{17.3} & \multirow{3}{*}{4.1} & \multirow{3}{*}{15.5} & \multirow{3}{*}{3.4} & Hand/toe grip & 290.10 & $0.000^{*}$ & 0.95 & \multirow{3}{*}{$\begin{array}{l}\text { Dominant, } \\
\text { non-dominant: } \\
\text { Hand grip } \\
\text { > Toe grip }\end{array}$} \\
\hline & & & & & & & & & & $\begin{array}{c}\text { Dominant/ } \\
\text { non-dominant }\end{array}$ & 4.26 & 0.058 & 0.23 & \\
\hline & & & & & & & & & & Interaction & 0.33 & 0.572 & 0.02 & \\
\hline \multirow{3}{*}{$\begin{array}{l}\text { Time to } \\
\text { maximal } \\
\text { force value }\end{array}$} & \multirow{3}{*}{ sec } & \multirow{3}{*}{1.69} & \multirow{3}{*}{1.10} & \multirow{3}{*}{1.79} & \multirow{3}{*}{1.24} & \multirow{3}{*}{1.59} & \multirow{3}{*}{1.07} & \multirow{3}{*}{1.54} & \multirow{3}{*}{1.00} & Hand/toe grip & 0.30 & 0.595 & 0.02 & \\
\hline & & & & & & & & & & $\begin{array}{c}\text { Dominant/ } \\
\text { non-dominant }\end{array}$ & 0.01 & 0.907 & 0.00 & \\
\hline & & & & & & & & & & Interaction & 0.13 & 0.724 & 0.01 & \\
\hline \multirow{3}{*}{$\begin{array}{l}\text { Time to } 90 \% \\
\text { maximal } \\
\text { force value }\end{array}$} & \multirow{3}{*}{ sec } & \multirow{3}{*}{0.45} & & & & & & & & Hand/toe grip & 27.17 & $0.000^{*}$ & 0.66 & Dominant \\
\hline & & & 0.24 & 0.46 & 0.32 & 0.89 & 0.41 & 0.97 & 0.80 & $\begin{array}{c}\text { Dominant/ } \\
\text { non-dominant }\end{array}$ & 0.16 & 0.699 & 0.01 & \\
\hline & & & & & & & & & & Interaction & 0.07 & 0.795 & 0.00 & Палाय giा \\
\hline & & & & & & & & & & Hand/toe grip & 335.29 & $0.000^{*}$ & 0.96 & Dominant \\
\hline $\begin{array}{l}\text { Integral force } \\
\text { for } 2 \mathrm{sec}\end{array}$ & $\mathrm{kg}$ & 1679.0 & 350.0 & 1616.7 & 239.1 & 525.1 & 161.0 & 469.3 & 123.8 & $\begin{array}{c}\text { Dominant/ } \\
\text { non-dominant }\end{array}$ & 3.08 & 0.101 & 0.18 & $\begin{array}{l}\text { non-dominant: } \\
\text { Hand grip }\end{array}$ \\
\hline & & & & & & & & & & Interaction & 0.02 & 0.886 & 0.00 & $1 \mathrm{P}$ \\
\hline
\end{tabular}

Note: ${ }^{*} p<0.05$.

Table 2. Pearson's correlations between dominant side and non-dominant side for parameters.

\begin{tabular}{ccc}
\hline & Hand grip & Toe grip \\
\cline { 2 - 3 } Maximal force value & Dominant $\times$ non-dominant & Dominant $\times$ non-dominant \\
\hline Time to maximal force value & $0.889^{*}$ & $0.762^{*}$ \\
Time to 90\% maximal force value & $0.690^{*}$ & 0.066 \\
Integral force for 2 sec & 0.242 & 0.032 \\
\hline
\end{tabular}

Note: ${ }^{*} p<0.05$. 
showed non-significant correlations between dominant and non-dominant sides in both grips.

\section{Discussion}

From previous studies, it was assumed that the force exertion characteristics and laterality related to hand and toe grip motions are different. The explosive force exertion characteristics in both grips were examined in this study.

Aoki \& Demura (2008) reported that in the load of 20\% - 70\% MVC, the peak velocity in the dominant side was higher than that in the non-dominant side in 20\% - 50\% MVC for hand grip, and in the non-dominant side in 20\% - 30\% MVC for elbow flexion. Kubota et al. (2012) reported that the laterality was found in controlled force exertion using 5\% - 25\% load of maximal handgrip strength. From the above previous reports, laterality may not be found in high loads. The present results did not show laterality in all parameters regarding explosive grip exertions. In addition, the relationships between the dominant and non-dominant sides during both grip exertions showed significance in parameters regarding maximal force value and integral force $(r=0.710-0.889)$, but not in the time to achieve near maximal force (time to $90 \%$ maximal force value) (hand grip: $r=0.242$, toe grip: $r=0.032$ ). Noguchi et al. (2009) reported that a degree of difference between the dominant and the nondominant hand was larger in controlled force exertion than in maximal handgrip strength. Thus, in explosive force exertion, laterality is found in parameters regarding time but not force.

When comparing the force exertions of the hand grip and toe grip, time reaching to maximal force value showed non-significant difference, but time to $90 \%$ maximal force value was shorter in the hand grip than in the toe grip. Demura et al. (1999) reported that the mean time to $90 \%$ maximal force value in explosive handgrip was $0.40 \mathrm{sec}$. The time in this study was $0.45 \mathrm{sec}$ (dominant hand) and $0.46 \mathrm{sec}$ (non-dominant hand) in the hand grip, and $0.89 \mathrm{sec}$ (dominant foot) and $0.97 \mathrm{sec}$ (non-dominant foot) in the toe grip. Demura et al. (1999) reported that an increase of force value during explosive hand grip exertion becomes slow at about $90 \%$ of maximal strength. Additionally, in this study the above phase in hand grip exertion was similar to that reported by Demura et al. (1999). However, an increase of force value in explosive toe grip just after exertion is slower than that in explosive hand grip, and it tended to slow from about 70\% of maximal strength. In short, the increasing phase of force exertion until near maximal force value in explosive toe grip is slow. In addition, time to maximal force value showed a significant relationship between the dominant side and non-dominant side in the hand grip, but not in the toe grip. The characteristics between dominant and non-dominant grip exertions until a force exertion value is reached explosively may have a similar tendency in the hand grip exertion, as compared with the toe grip exertion.

Menz et al. (2006) measured toe plantar flexion strength using the pressure platform. To examine the differences between the grip movement of the fingers and toes, toe grip strength in this study was measured after creating a situation in which the subjects were likely to voluntarily grip the bar of a toe finger dynamometer. Compared with the hand grip, gripping the bar with toes is a relatively unusual movement. Hence, the above may have affected the differences of both the hand grip and toe grip. In the future, it will be necessary to use the pressure platform to measure toe strength with a movement similar to walking.

\section{Conclusion}

In conclusion, maximal force value and integral force for $2 \mathrm{sec}$ in explosive hand grip exertions are larger than those in explosive toe grip. Time to $90 \%$ maximal force value in the explosive hand grip exertions is shorter than that in the explosive toe grip. A significant relationship between dominant and non-dominant sides is found in maximal force value and integral force for 2 sec in both grips, but not in the time to $90 \%$ maximal force values. Laterality is found in time performances, but not force performances in the hand and toe grips.

\section{References}

Aoki, H., \& Demura, S. (2008). Characteristics and Lateral Dominance of Hand Grip and Elbow Flexion Powers in Young Male Adults. Journal of Physiological Anthropology, 27, 201-206. http://dx.doi.org/10.2114/jpa2.27.201

Demura, S., Miyaguchi, K., \& Aoki, H. (2010a). The Difference in Output Properties between Dominant and NondominantLimbs as Measured by Various Muscle Function Tests. The Journal of Strength and Conditioning Research, 24, 28162820. http://dx.doi.org/10.1519/JSC.0b013e3181e38293 
Demura, S., Sato, S., \& Sugiura, H. (2010b). Lower Limb Laterality Characteristics Based on the Relationship between Activities and Individual Laterality. Gazzetta Medica Italiana-Archivioper le ScienzeMediche, 169, 181-191.

Demura, S., Sato, S., \& Nagasawa, Y. (2009). Re-Examination of Useful Items for Determining Hand Dominance. GazzettaMedicaItaliana-Archivioper le ScienzeMediche, 168, 169-177.

Demura, S., Yamaji, S., Minami, M., Nagasawa, Y., Kita, I., \& Matsuzawa J. (1999). Examining Reproducibility of ForceExertion Pattern and Reliability of Force-Time Parameters in the Development Phase during Static Explosive Grip Exertion. Japanese Journal of Physical Fitness and Sports Medicine, 48, 493-500.

Holmes, J. R., \& Alderink, G. J. (1984). Isokinetic Strength Characteristics of the Quadriceps Femoris and Hamstring Muscles in High School Students. Physical Therapy, 64, 914-918.

Hughes, J., Clark, P., \& Klenerman, L. (1990). The Importance of the Toes in Walking. The Journal of Bone and Joint Surgery (British), 72-B, 245-251.

Kubota, H., \& Demura, S. (2011). Gender Differences and Laterality in Maximal Handgrip Strength and Controlled Force Exertion in Young Adults. Health, 3, 684-688. http://dx.doi.org/10.4236/health.2011.311115

Kubota, H., Demura, S., \& Kawabata, H. (2012). Laterality and Age-Level Differences between Young Women and Elderly Women in Controlled Force Exertion (CFE). Archives Gerontology and Geriatrics, 54, e68-e72. http://dx.doi.org/10.1016/j.archger.2011.06.027

Menz, H. B., Zammit, G. V., Munteanu, S. E., \& Scott, G. (2006). Plantarflexion Strength of the Toes: Age and Gender Differences and Evaluation of a Clinical Screening Test. Foot and Ankle International, 27, 1103-1108.

Miyaguchi, K., \& Demura, S. (2008). Lateral Dominance of Stretch-Shortening Cycle Performance in Unilateral and Bilateral Athletes. The Journal of Sports Medicine and Physical Fitness, 48, 24-30.

Nakada, M., \& Demura, S. (2013). Comparison of Force Exertion Characteristics of Sustained Hand Grip and Toe Grip. American Journal of Sports Science and Medicine, 1, 28-32.

Nakada, M., Demura, S., Yamaji, S., \& Nagasawa, Y. (2005). Examination of the Reproducibility of Grip Force and Muscle Oxygenation Kinetics on Maximal Repeated Rhythmic Grip Exertion. Journal of Physiological Anthropology and Applied Human Science, 24, 1-6. http://dx.doi.org/10.2114/jpa.24.1

Noguchi T., Demura, S., \& Aoki, H. (2009). Superiority of the Dominant and Nondominant Hands in Static Strength and Controlled Force Exertion. Perceptual and Motor Skills, 109, 339-346. http://dx.doi.org/10.2466/pms.109.2.339-346

Yamaji, S., Demura, S., Nagasawa, Y., Nakada, M., Yoshimura, Y., Matsuzawa, J., \& Toyoshima, Y. (2000). Examination of the Parameters of Static Muscle Endurance on Sustained Static Maximal Hand Gripping. Japan Journal of Physical Education, 45, 695-706.

Yamaji, S., Demura, S., Nagasawa, Y., Nakada, M., \& Kitabayashi, T. (2002). The Effect of Measurement Time When Evaluating Static Muscle Endurance during Sustained Static Maximal Gripping. Journal of Physiological Anthropology and Applied Human Science, 21, 151-158. http://dx.doi.org/10.2114/jpa.21.151 
Scientific Research Publishing (SCIRP) is one of the largest Open Access journal publishers. It is currently publishing more than 200 open access, online, peer-reviewed journals covering a wide range of academic disciplines. SCIRP serves the worldwide academic communities and contributes to the progress and application of science with its publication.

Other selected journals from SCIRP are listed as below. Submit your manuscript to us via either submit@scirp.org or Online Submission Portal.
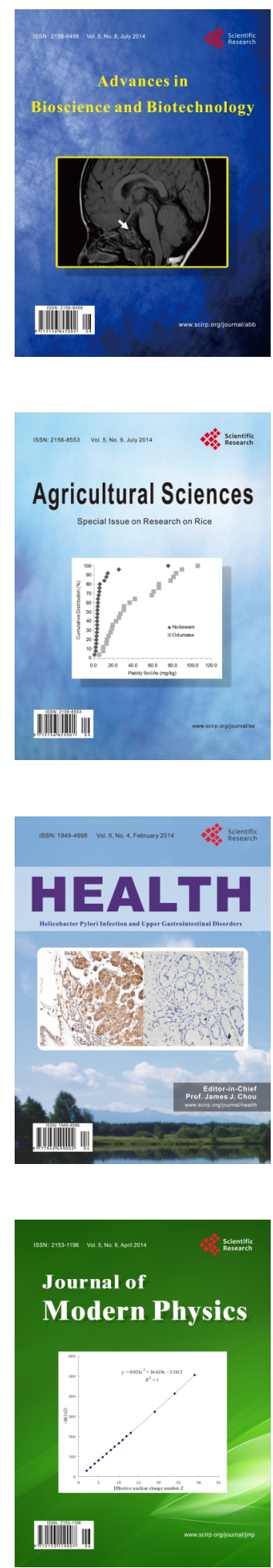
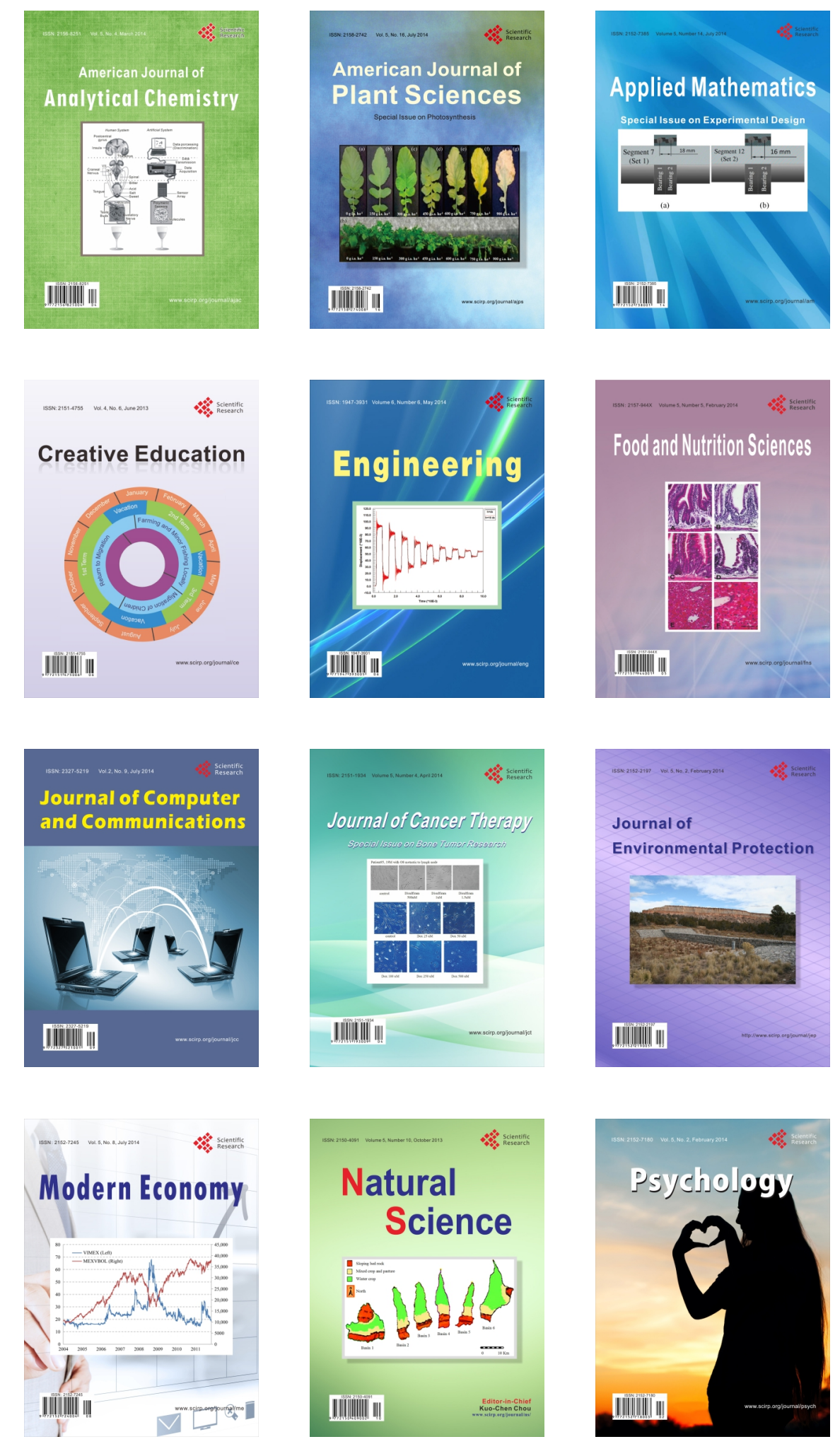